\title{
SOROTAN KAJIAN KESEDIAAN DAN KEPERLUAN GURU BAHASA MELAYU DALAM PELAKSANAAN KEMAHIRAN BERFIKIR ARAS TINGGI (KBAT) DI BILIK DARJAH
}

\author{
Order Thinking Skills (HOTS) \\ Farah Aziana Abdul Aziz \\ farah_aziana@yahoo.com \\ Fadzilah Abd Rahman \\ sisfadzilah@gmail.com \\ Fakulti Pengajian Pendidikan \\ Universiti Putra Malaysia
}

Literature Review: Readiness and Needs of Teachers in Implementing Higher

\begin{abstract}
ABSTRAK
Kertas ini membincangkan tentang kesediaan dan keperluan guru dalam pelaksanaan kemahiran berfikir aras tinggi (KBAT) dalam proses pengajaran dan pemudahcaraan (PdPc) bahasa Melayu di sekolah. Memandangkan guru merupakan individu yang bertanggungjawab dalam membentuk dan mendidik murid di sekolah mengikut keperluan semasa pendidikan, maka peranan guru sangat dititikberatkan dalam menjayakan pelaksanaan KBAT dalam semua mata pelajaran. Kesediaan guru dalam melaksanakan pengajaran berasaskan KBAT sangat penting bagi membolehkan mereka mendidik murid menguasai KBAT yang mana merupakan salah satu aspek yang perlu dikuasai dalam menuju abad ke-21. Keperluan guru dalam merealisasikan pelaksanaan KBAT secara berkesan perlu diberi perhatian agar hasrat kerajaan untuk melahirkan generasi berfikir pada aras tinggi dapat dicapai. Kajian ini menggunakan kaedah analisis dokumen berdasarkan sorotan-sorotan kajian lepas yang berkaitan dengan kesediaan dan keperluan guru bahasa Melayu dalam melaksanakan pengajaran berunsur KBAT. Hasil kajian mendapati bahawa kebanyakan guru masih belum bersedia melaksanakan KBAT dalam pengajarannya disebabkan oleh kurang pendedahan tentang cara pelaksanaan KBAT dalam PdPc, tidak tahu kaedah untuk menerapkan KBAT dalam PdPc dan juga dibebani dengan pelbagai tugas lain yang menghalang untuk melaksanakan PdPc berasaskan KBAT dilaksanakan dengan baik. Dapatan kajian ini juga turut memperincikan beberapa keperluan yang diperlukan oleh guru dalam melaksanakan pengajaran berasaskan KBAT.
\end{abstract}

Kata kunci: Kemahiran Berfikir Aras Tinggi (KBAT); Keperluan Guru; Kesediaan Guru; Teori Taksonomi Bloom

\begin{abstract}
This paper discuss on readiness and needs of teacher in high order thinking skills (HOTS) implementation in process PdPc in school. As teacher is individual who responsible in shaping and educating student in school according to current education need, so role of teacher terribly emphasized in succeeding HOTS implementation in all subjects. Teacher readiness in those educating student control HOTS which is one of the aspects that need to be controlled in aiming $21^{\text {st }}$ Century. Needs of teachers in realizing HOTS implementation effectively need to be given attention so that government's desire to produce generation think in high level can be achieved. This study uses a document analysis method based on the previous research highlights related to the readiness and needs of Malay language teachers in implementing HOTS teaching. The findings show that most teachers are still not ready to implement HOTS in their teaching due to lack of exposure on the implementation of HOTS in lesson, not knowing how to implement HOTS in lesson and also burdened with various other tasks that prevented the implementation of lesson based on HOTS. The findings of this study also detail some of the needs that teachers need to implement on HOTS based teaching.
\end{abstract}


Keywords: Higher Order Thinking Skills (HOTS); Needs of Teacher; Readiness of Teacher; Taxonomy Bloom Theory

\section{PENGENALAN}

Berdasarkan Pelan Pembangunan Pendidikan Malaysia (2013-2025), terdapat enam ciri yang digariskan untuk melahirkan generasi yang menuju abad ke-21, iaitu mempunyai kemahiran memimpin, kemahiran dwibahasa, etika dan kerohanian, identiti sosial, pengetahuan dan kemahiran berfikir (Kementerian Pendidikan Malaysia, 2014). PPPM (2013-2025) merupakan pelan pendidikan Malaysia jangka panjang, iaitu selama 13 tahun bagi memastikan sistem pendidikan Malaysia lebih baik dan stabil pada masa akan datang. Bagi melahirkan generasi yang mempunyai kemahiran berfikir, kemahiran berfikir aras tinggi (KBAT) telah diperkenalkan pada tahun 2013. Realitinya, di Malaysia kemahiran berfikir telah diaplikasikan di semua sekolah sejak tahun 1994. Sebelum KBAT diperkenalkan, kemahiran berfikir secara kritis dan kreatif (KBKK) telah diaplikasikan dan kemudiannya pada tahun 2011, KSSR dan KSSM pula telah diperkenalkan.

Kemahiran berfikir aras tinggi (KBAT) di Malaysia diperkenalkan disebabkan oleh desakan persaingan murid Malaysia di peringkat global dalam sistem pendidikan Malaysia jauh ketinggalan berbanding sistem pendidikan negara-negara lain. Tambahan pula, kedudukan Malaysia dalam PISA juga jauh ketinggalan berbanding negara lain oleh kerana soalan PISA berbentuk KBAT dan memerlukan peserta berfikir dan memberi ulasan secara mendalam. Justeru, desakan demi desakan KBAT telah diterapkan dalam semua mata pelajaran di Malaysia bagi membolehkan Malaysia setanding dengan negara-negara lain dan meningkatkan sistem pendidikan ke arah yang lebih maju dan berkembang (Abdul Halim Abdullah, Johari Surif dan Norhasniza Ibrahim, 2014).

Namun begitu, dalam menjayakan hasrat kerajaan Malaysia menerapkan KBAT dalam semua subjek di sekolah, kesediaan guru untuk memikul tanggungjawab ini perlu diberi penekanan terlebih dahulu sebelum mengambil kira penerimaan murid terhadap PdPc berasaskan KBAT. Hal ini demikian kerana guru yang memainkan peranan utama sebagai ajen perantaraan bagi murid menguasai KBAT. Oleh hal yang demikian, penelitian terhadap kesediaan guru dalam pelaksanaan KBAT dan keperluan guru dalam menjayakan pelaksanaan KBAT perlu diberi perhatian secara menyeluruh agar hasrat kerajaan untuk menambah baik sistem pendidikan Malaysia berjalan dengan lancar. Dapatan kajian Nor Hasmaliza Hasan dan Zamri Mahamod (2016) mendapati guru-guru bahasa Melayu menunjukkan kesediaan yang memberangsangkan dalam penerapan KBAT dalam PdPc bahasa Melayu, iaitu kesediaan guru dari segi pemahaman tentang KBAT menunjukkan berada di tahap sederhana manakala dari segi pengetahuan dan pelaksanaan KBAT dalam PdPc bahasa Melayu pula menunjukkan berada di tahap tinggi. Bagi meningkatkan tahap pemahaman guru bahasa Melayu tentang KBAT, pendedahan tentang konsep KBAT, pengajaran KBAT dan inti pati dalam pengajaran KBAT perlu diperluaskan agar guru bahasa Melayu dapat menerapkan KBAT dalam pengajarannya secara berkesan.

\section{KEMAHIRAN BERFIKIR ARAS TINGGI (KBAT)}

Kemahiran berfikir aras tinggi (KBAT) merupakan salah satu kemahiran yang ditekankan di seluruh persada dunia. Justeru, KBAT merupakan tahap pemikiran yang diperlukan dalam membentuk generasi abad ke-21 yang cerdas, kreatif dan berinovatif serta berpotensi untuk bersaing di peringkat global (Abdul Rasid Jamiam, Shamsudin Othman, Azhar Mohd Sabil dan Juanes Masamin, 2016; Suzana Abd Mutalib dan Mohammad Zeeree Kanreng, 2017). KBAT membolehkan seseorang bukan sekadar mengingat dan memahami sesuatu maklumat malah berpotensi lebih daripada itu, iaitu berpotensi menggunakan, mentafsir, memanipulasikan, menginterpretasikan dan mengubahsuai maklumat tersebut dalam konteks yang lain.

Berdasarkan Jadual 1, terdapat beberapa penjelasan tentang definisi KBAT menurut tokoh telah dihuraikan. Antaranya menurut Rajendran Nagappan (2002), KBAT merujuk kepada seseorang yang dapat memahami, menterjemah, menganalisis dan memanipulasikan maklumat serta menyelesaikan 
sesuatu masalah dengan pendekatan yang bukan rutin. Manakala, Halimah Md Shariff (2009) pula menyatakan bahawa KBAT merujuk kepada penggunaan minda secara meluas bagi menghadapi masalah-masalah baharu dengan mentafsir, menganalisis atau memanipulasikan maklumat untuk menjawab soalan mahupun menyelesaikan sesuatu masalah yang dihadapi. KBAT juga turut didefinisikan oleh Bakry, Md. Nor Bakar dan Firdaus (2013) sebagai kemampuan berfikir seseorang yang bukan sahaja merujuk kepada mengingat, tetapi termaksud juga berkemampuan berfikir kritis, menganalisis dan membuat penilaian KBAT juga merujuk kepada keupayaan dalam mengaplikasikan pengetahuan, kemahiran dan nilai yang diterapkan dalam proses pengajaran dan pemudahcaraan di dalam bilik darjah merangkumi juga aspek pentafsiran pembelajaran (Afinde Othman, 2016). Selain itu, Logeswari Arumugam, Ainon Omar, Raja Nur Safinas Raja Harun, dan Nurfilzah Zainal (2016), pula telah menjelaskan bahawa kemahiran berfikir aras tinggi merujuk kepada satu proses pemikiran kognitif yang lengkap bermula daripada tahap pemikiran rendah sehingga ke tahap pemikiran yang tinggi, yang mana dapat menjalinkan sesuatu maklumat seterusnya menganalisis, generalisasi, sintesis dan menginterpretasikannya menjadi sesuatu idea yang baru. Dapat disimpulkan bahawa secara umumnya, definisi KBAT merujuk kepada kemampuan seseorang individu menyelesaikan sesuatu masalah, membuat keputusan dan melaksanakan sesuatu perkara dengan berfikir secara kreatif, inovatif, tidak terhad kepada sesuatu keadaan sahaja malah meluas dan terbuka selagi tidak melangkaui logik akal fikiran manusia.

JADUAL 1 Definisi Kemahiran Berfikir Aras Tinggi (KBAT)

\begin{tabular}{|c|c|c|c|}
\hline Bil. & Nama Penulis & Tahun & Definisi KBAT \\
\hline 1 & $\begin{array}{l}\text { Rajendran } \\
\text { Nagappan }\end{array}$ & 2002 & $\begin{array}{l}\text { "... seseorang yang dapat memahami, menterjemah, } \\
\text { menganalisis dan memanipulasikan maklumat serta } \\
\text { menyelesaikan masalah dengan pendekatan bukan rutin". }\end{array}$ \\
\hline 2 & $\begin{array}{l}\text { Halimah } \quad \text { Md } \\
\text { Shariff }\end{array}$ & 2009 & $\begin{array}{l}\text { “... penggunaan minda secara meluas bagi menghadapi } \\
\text { masalah-masalah baharu dengan mentafsir, menganalisis atau } \\
\text { memanipulasikan maklumat untuk menjawab soalan mahupun } \\
\text { menyelesaikan sesuatu masalah yang dihadapi”. }\end{array}$ \\
\hline 3 & $\begin{array}{l}\text { Bakry, Md. Nor } \\
\text { Bakar \& Firdaus }\end{array}$ & 2013 & $\begin{array}{l}\text { “... kemampuan berfikir yang bukan sahaja merujuk kepada } \\
\text { mengingat tetapi termaksud juga berkemampuan berfikir } \\
\text { kritis, menganalisis dan membuat penilaian". }\end{array}$ \\
\hline 4 & Afinde Othman & 2016 & $\begin{array}{l}\text { "... keupayaan dalam mengaplikasikan pengetahuan, } \\
\text { kemahiran dan nilai yang diterapkan dalam PdPc". }\end{array}$ \\
\hline 5 & $\begin{array}{l}\text { Logeswari } \\
\text { Arumugam, Ainon } \\
\text { Omar, Raja Nur } \\
\text { Safinas Raja } \\
\text { Harun \& Nurfilzah } \\
\text { Zainal }\end{array}$ & 2016 & $\begin{array}{l}\text { "... satu proses pemikiran kognitif yang lengkap bermula } \\
\text { daripada tahap pemikiran rendah sehingga ke tahap pemikiran } \\
\text { yang tinggi, yang dapat menjalinkan sesuatu maklumat } \\
\text { seterusnya menganalisis, generalisasi, sintesis dan } \\
\text { menginterpretasikan menjadi idea baru". }\end{array}$ \\
\hline
\end{tabular}

Menurut Halimah Md Shariff (2009) dan Rizki Ananda dan Fadhilaturrahmi (2017), Bloom telah mengklasifikasikan aras keupayaan kognitif kepada enam aras pemikiran, iaitu pengetahuan, kefahaman, aplikasi, analisis, sintesis dan penilaian. Aras pengetahuan ialah peringkat seseorang mengingat bahan-bahan yang telah dipelajari dan dikuasai dan ini merupakan peringkat pemikiran yang paling rendah. Pada peringkat ini, seseorang akan mengingat perkara dan maklumat yang relevan dalam jangka panjang. Aras pemahaman pula boleh didefinisikan sebagai peringkat seseorang mengenal pasti maksud bahan-bahan tertentu dan ini merupakan aras pemikiran kedua terendah. Pada peringkat ini 
juga, seseorang dapat menyesuaikan apa-apa yang telah dipelajari menerusi komunikasi lisan, bacaan dan grafik dalam memahami sesuatu perkara.

Seterusnya aras aplikasi, iaitu peringkat yang mana seseorang boleh menggunakan maklumat yang dipelajari dalam satu situasi yang baharu dan konkrit dan ini merupakan aras pemikiran yang lebih tinggi berbanding aras pemahaman dan pengetahuan. Pada peringkat ini, seseorang berkemampuan menggunakan sesuatu proses ataupun kaedah yang digunakan dalam situasi yang berlainan. Aras analisis pula, seseorang boleh mengasingkan bahan ke dalam bahagian-bahagian komponennya supaya struktur organisasinya mudah difahami dan peringkat ini merupakan aras yang lebih tinggi berbanding aras aplikasi dan pemahaman. Pada peringkat ini, seseorang dapat menghubungkaitkan antara satu item dengan item yang lain dalam membentuk suatu hubungan yang saling berkaitan.

Aras sintesis pula merujuk kepada peringkat yang mana seseorang boleh membina bahagianbahagian bersama ataupun gabungan elemen-elemen bagi membentuk satu keseluruhan yang baharu dan peringkat ini merupakan aras yang lebih intelektual berbanding aras analisis dan aplikasi. Pada peringkat ini, seseorang dapat menyatukan sesuatu elemen secara bersama-sama untuk membentuk sesuatu struktur baru yang logik, fungsional dan bersesuaian. Akhir sekali, aras penilaian yang mana aras yang tertinggi dalam aras pemikiran kognitif yang mana di peringkat ini membolehkan seseorang membuat pertimbangan atau pengadilan dengan menggunakan kaedah piawai bagi menentukan kesesuaian, ketepatan, kecekapan, keberkesanan tentang sesuatu nilai, pendapat, penyelesaian dan sebagainya. Pada peringkat ini, seseorang dapat membuat penilaian terhadap sesuatu perkara dengan melihat perkaitan dan jurang yang ada. Enam aras keupayaan kognitif yang digariskan dalam Teori Taksonomi Bloom adalah seperti dalam rajah 1.

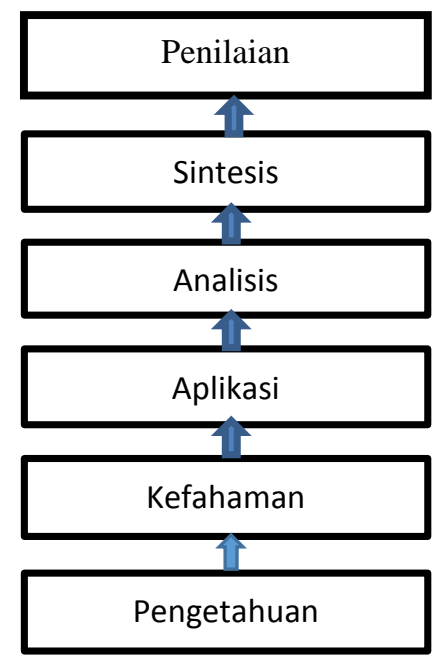

RAJAH 1 Aras Keupayaan Kognitif Bloom Sumber: Anderson \& Kathwohl (2001)

Walau bagaimanapun, oleh kerana keperluan global memerlukan murid menguasai kemahiran berfikir sebagaimana yang digariskan dalam keperluan abad ke-21, Semakan Hierarki Taksonomi Bloom oleh Anderson diguna pakai bagi meningkatkan kemahiran berfikir murid dalam mengaplikasikan ilmu pengetahuan dan berfikir secara kritis dan kreatif dalam kehidupan harian (Bahagian Pembangunan Kurikulum, 2014). Kemahiran berfikir berdasarkan Semakan Hierarki Taksonomi Bloom oleh Anderson pada tahun 1900, iaitu mengingat, memahami, mengaplikasi, menganalisis, menilai dan mencipta seperti dalam rajah 2. 


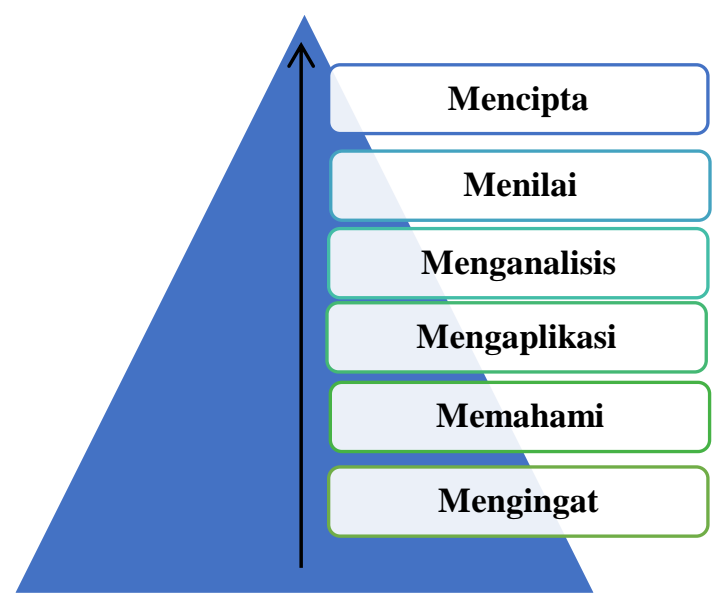

RAJAH 2 Taksonomi Bloom Semakan Semula Sumber: Anderson \& Kathwohl (2001)

\section{KEMAHIRAN BERFIKIR ARAS TINGGI DI MALAYSIA}

Berdasarkan Taksonomi Bloom Semakan Anderson \& Krathwohl (2001), daripada enam aras pemikiran kognitif manusia, beliau telah membahagikannya kepada dua bahagian, iaitu tiga aras terbawah merupakan kemahiran berfikir aras rendah (KBAR) dan tiga aras teratas merupakan kemahiran berfikir aras tinggi (KBAT). Walau bagaimanapun, menurut Nooriza Kassim dan Effandi Zakaria (2015) dan Wan Nor Shairah Sharuji dan Norazah Mohd Nordin (2017), di Malaysia KBAT merujuk kepada 4 aras teratas taksonomi tersebut, iaitu mengaplikasi, menganalisis, menilai dan mencipta. Tambahan pula, sebelum ini kajian oleh Rajendran Nagappan (1998) telah menjelaskan bahawa berdasarkan Taksonomi Bloom, enam aras kognitif telah dibahagikan kepada dua tahap, iaitu aras pengetahuan dan aras kefahaman digolongkan dalam Kemahiran Berfikir Aras Rendah (KBAR) manakala aras aplikasi, analisis, sintesis dan penilaian digolongkan dalam Kemahiran Berfikir Aras Tinggi (KBAT). Jadual 2 di bawah merupakan Taksonomi KBAT dan KBAR oleh Rajendran yang boleh membantu guru dalam merancang dan mengendalikan bilik darjah.

JADUAL 2 Taksonomi KBAT dan KBAR

\begin{tabular}{|c|c|c|}
\hline Taksonomi Bloom & KBAT dan KBAR & Keterangan \\
\hline Pengetahuan & \multirow[t]{2}{*}{$\begin{array}{l}\text { Kemahiran Berfikir Aras } \\
\text { Rendah }\end{array}$} & \multirow[b]{2}{*}{$\begin{array}{l}\text { - } \quad \text { Penggunaan potensi minda yang terhad. } \\
\text { - } \quad \text { Aplikasi rutin dan mekanistik. } \\
\text { - Operasi berulang seperti menyenaraikan maklumat } \\
\text { yang pernah dipelajari sebelum, mengaplikasikan } \\
\text { peraturan prosedur dan aktiviti mental rutin dan } \\
\text { algoritmik yang lain. } \\
\text { Ia memerlukan pelajar untuk menghuraikan, } \\
\text { membanding-bezakan, menyingkatkan, } \\
\text { menghubungkan, mengaplikasikan dan } \\
\text { menyelesaikan masalah. }\end{array}$} \\
\hline Kefahaman & & \\
\hline Aplikasi & \multirow[t]{4}{*}{$\begin{array}{l}\text { Kemahiran Berfikir Aras } \\
\text { Tinggi }\end{array}$} & \multirow{4}{*}{$\begin{array}{l}\text { - Penggunaan potensi minda untuk menangi cabaran } \\
\text { baru. } \\
\text { - Seseorang perlulah memahami, menterjemah, } \\
\text { menganalisis, dan memanipulasikan maklumat. } \\
\text { - Memerlukan pelajar menilai maklumat secara } \\
\text { kritis, membuat inferens, dan membuat } \\
\text { generalisasi. }\end{array}$} \\
\hline Analisis & & \\
\hline Sintesis & & \\
\hline Penilaian & & \\
\hline
\end{tabular}




\begin{tabular}{|l|ll|}
\hline & $\bullet$ & $\begin{array}{l}\text { Pelajar menghasilkan komunikasi asli, membuat } \\
\text { ramalan, mencadangkan penyelesaian, mencipta, } \\
\text { menyelesaikan masalah berkaitan kehidupan }\end{array}$ \\
& seharian, menilai idea, melahirkan pendapat, \\
& membuat pilihan dan membuat keputusan. \\
\hline
\end{tabular}

Sumber: Rajendran Nagappan (2002)

Berikutan dengan pembentukan pembelajaran Abad ke-21 di semua sekolah di Malaysia, maka terhasil pembentukan edisi semakan Taksonomi Bloom pada tahun 2002 oleh Anderson dan Krathwohl, dan telah mengemas kini enam aras pemikiran Bloom kepada kata kerja dan juga membahagikan empat aras teratas ke dalam kelompok kemahiran berfikir aras tinggi (KBAT) dan dua aras terendah ke dalam kelompok kemahiran berfikir aras rendah (KBAR). Rajah 3 menunjukkan perbandingan dua taksonomi tersebut.

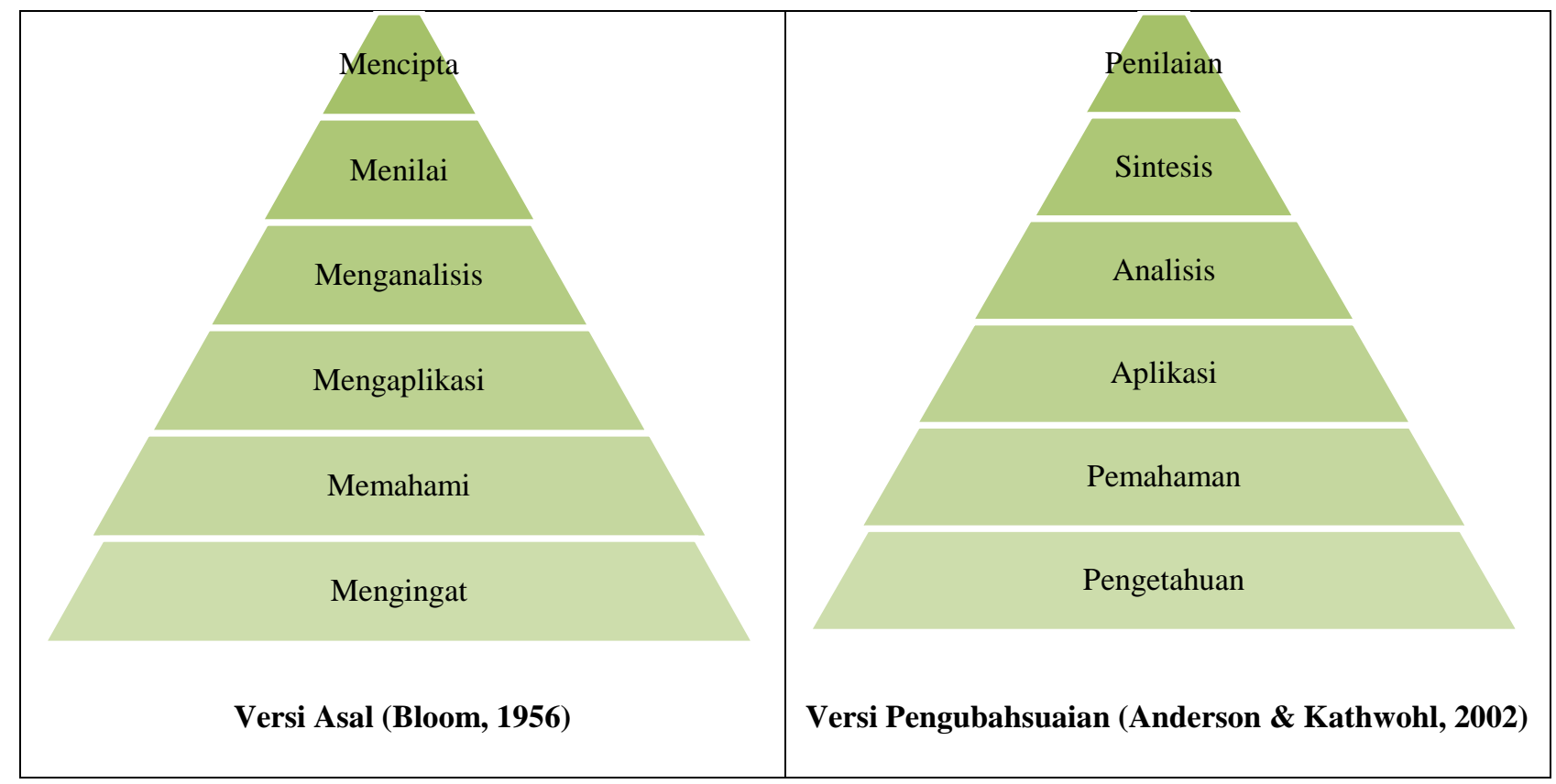

RAJAH 3 Perbandingan Taksonomi Bloom Versi Lama dan Versi Baru Sumber: Wan Nor Shairah Sharuji \& Norazah Mohd Nordin (2017)

Kemahiran Berfikir Aras Tinggi (KBAT) diperkenalkan pada tahun 2013 di Malaysia atas desakan persaingan sengit di peringkat global, iaitu kedudukan Malaysia dalam sistem pendidikan ASEAN dan Programme for international Student Assesment (PISA) jauh ketinggalan berbanding dengan negara-negara lain. Oleh hal demikian, Pelan Pembangunan Pendidikan Malaysia 2013-2025 telah menekankan bahawa semua guru perlu mempersiapkan diri dari segi pengetahuan dan juga kemahiran dalam menjayakan pelaksanaan KBAT di Malaysia agar dapat melahirkan generasi yang menguasai KBAT sesuai dengan keperluan abad ke-21 di samping KBAT merupakan salah satu ciri daripada tujuh ciri yang digariskan oleh Kementerian Pendidikan Malaysia pada tahun 2014.

Hal ini disokong oleh kajian Wan Nor Shairah Sharuji \& Norazah Mohd Nordin (2017), yang menyatakan bahawa Malaysia tidak tergolong dalam negara ASEAN yang mempunyai sistem pendidikan yang terbaik sebagaimana negara Korea, China dan Singapura yang mencatat kedudukan terbaik ASEAN dalam sistem pendidikan. Oleh hal yang demikian, penekanan terhadap pelaksanaan KBAT dalam semua mata pelajaran di peringkat pendidikan rendah sehinggalah di peringkat pendidikan tinggi dititikberatkan dan guru merupakan individu yang difokuskan untuk menjayakan matlamat ini. Peranan para guru sangat penting bagi meningkatkan sistem pendidikan Malaysia di 
persada antarabangsa dengan kesediaan menerapkan KBAT dalam pengajaran bahasa Melayu khususnya dan begitu juga dalam subjek-subjek lain. Walau bagaimanapun, dalam memberi tumpuan terhadap kesediaan guru dalam melaksanakan PdPc berasaskan KBAT, keperluan guru dalam menjayakan penerapan KBAT dalam semua subjek tidak boleh dipandang enteng dan perlu disediakan seboleh mungkin.

\section{METODOLOGI}

Dalam kertas kerja ini, kaedah kualitatif analisis dokumen digunakan, iaitu analisis beberapa dapatan jurnal berkaitan dengan pengajaran berasaskan kemahiran berfikir aras tinggi (KBAT) kesediaan guru dalam melaksanakan pengajaran berasaskan KBAT dan keperluan guru dalam melaksanakan PdPc bahasa Melayu khususnya sama ada di peringkat pendidikan rendah mahupun di peringkat pendidikan menengah. Oleh hal yang demikian, kertas kerja ini telah merangkumkan serta menyimpulkan dapatandapatan kajian yang diperoleh menerusi penelitian terhadap beberapa jurnal yang berkaitan dengan kajian ini. Berdasarkan pengumpulan sorotan-sorotan kajian daripada beberapa jurnal ini membolehkan pengkaji lain untuk mengisi lompang-lompang kosong dalam pengkajian berkaitan dengan pengajaran bahasa Melayu berasaskan KBAT dari sudut yang berbeza, misalnya melalui pendedahan tentang kesediaan dan keperluan guru dalam melaksanakan pengajaran KBAT, pengkaji dapat merangka kajian berkaitan dengan strategi penerapan KBAT dalam pengajaran guru bahasa Melayu.

\section{KEMAHIRAN BERFIKIR ARAS TINGGI (KBAT) DALAM KURIKULUM BAHASA MELAYU}

Pelaksanaan Kemahiran berfikir aras tinggi (KBAT) dalam kurikulum bahasa Melayu tidak kiralah di peringkat pendidikan rendah ataupun di peringkat menengah merangkumi tiga aspek utama, iaitu penerapan KBAT dalam kemahiran mendengar dan bertutur, kemahiran membaca dan kemahiran menulis serta dua aspek lain, iaitu aspek seni bahasa dan aspek tatabahasa. Bagi menerapkan KBAT dalam PdPc Bahasa Melayu, perkara yang paling utama para guru perlu membuat pelbagai perancangan bagi menjayakan pelaksanaan KBAT dalam pedagogi.

Kementerian Pendidikan Malaysia (2013) dan Buletin Transformasi Pendidikan Malaysia (2015), telah menyenaraikan beberapa perancangan dan panduan kepada guru bagi melicinkan proses pengajaran mereka dengan mengaplikasikan KBAT. Perancangan dan panduan awal sebelum guru menjalankan PdPc, guru perlu merujuk standard pembelajaran berasaskan KBAT dengan mengenal pasti elemen KBAT dalam standard pembelajaran. Guru bahasa Melayu juga perlu menyatakan objektif pembelajaran secara eksplisit dan menyediakan beberapa aktiviti PdPc yang menggalakkan murid menggunakan KBAT. Alat bantu yang dapat meningkatkan pemikiran murid juga perlu disediakan oleh guru agar proses pembelajaran berasaskan KBAT dapat dilaksanakan dengan baik dan berkesan.

Semasa proses PdPc berlangsung pula, guru bahasa Melayu perlu menyesuaikan alat berfikir yang sesuai agar murid dapat berfikir ke tahap yang lebih tinggi. Guru bahasa Melayu juga perlu mengemukakan soalan dalam pelbagai aras pemikiran supaya murid terbiasa dengan soalan-soalan yang menjurus ke arah KBAT. Tidak lupa juga, guru mestilah mewujudkan suasana pembelajaran yang dapat membantu murid menggunakan KBAT. Soalan pentaksiran murid juga perlu dipastikan agar merangkumi soalan-soalan berasaskan KBAT. Akhir sekali, guru haruslah sentiasa membuat refleksi terhadap keberkesanan pelaksanaan PdPc berasaskan KBAT agar matlamat untuk menerapkan KBAT dalam kalangan murid terlaksana dengan jayanya.

Unsur kemahiran berfikir aras tinggi (KBAT) diserap dalam PdPc bahasa Melayu melalui aktiviti di dalam bilik darjah, soalan tugasan, latihan dan juga projek pentaksiran formatif (Suzana Abd Mutalib dan Mohammad Zeeree Kanreng, 2017). Penerapan KBAT menerusi aktiviti di dalam bilik darjah yang sering dilaksanakan oleh guru meliputi aktiviti soal jawab lisan berunsurkan KBAT, soalan latihan berkaitan KBAT dan soalan tugasan yang merangkumi KBAT. Pembinaan instrumen pentaksiran pula mestilah berdasarkan aras KBAT yang merangkumi aras domain kognitif, efektif dan psikomotor. Oleh hal yang demikian, pelaksanaan KBAT dalam PdPc Bahasa Melayu dapat dijalankan 
dengan sistematik dan teratur dengan menerapkan KBAT dalam setiap aktiviti murid bermula dengan aktiviti di bilik darjah, latihan secara individu mahupun berkumpulan, pelbagai tugasan dan pentaksiran.

Sejak KBAT dilaksanakan di peringkat pendidikan rendah dan juga di peringkat pendidikan menengah, peratusan soalan KBAT dalam peperiksaan UPSR dan SPM meningkat tahun demi tahun, iaitu soalan KBAT dalam peperiksaan UPSR daripada 10 peratus pada tahun 2013 dan meningkat sehingga 40 peratus pada tahun 2016 manakala soalan KBAT dalam peperiksaan SPM daripada 10 peratus pada tahun 2013 dan meningkat sehingga 50 peratus pada tahun 2016 (Kementerian Pendidikan Malaysia, 2014). Hal ini menunjukkan bahawa pelaksanaan PdPc berasaskan KBAT dan penerimaan terhadap penerapan KBAT dalam setiap aktiviti pembelajaran semakin diterima ramai dan sangat memberangsangkan. Dapatlah dibuktikan menerusi kenyataan oleh Raja Noraina Raja Rahim dalam artikelnya bertajuk "KBAT di Landasan Tepat" (2018) menjelaskan bahawa keputusan SPM 2017 menunjukkan 66 peratus calon menguasai KBAT dengan baik, iaitu 27 peratus menguasai KBAT pada tahap tinggi, 39 peratus tahap sederhana dan 34 peratus pada tahap rendah.

Dapat disimpulkan bahawa penerapan KBAT dalam PdPc bahasa Melayu lebih menjurus kepada tiga elemen utama iaitu, dalam PdPc kemahiran mendengar dan bertutur, kemahiran membaca dan kemahiran menulis. Bagi melancarkan pengaplikasian KBAT dalam PdPc, guru Bahasa Melayu mestilah membuat persiapan dan perancangan awal untuk memastikan penerapan KBAT dapat dilaksanakan dengan jayanya. Tambahan pula, keputusan SPM pada tahun 2017 telah membuktikan bahawa penerapan KBAT dalam PdPc sangat memberangsangkan dan mengagumkan.

\section{KESEDIAAN GURU DALAM KEMAHIRAN BERFIKIR ARAS TINGGI (KBAT)}

Kesediaan guru dalam menerapkan Kemahiran Berfikir Aras Tinggi (KBAT) dalam pengajaran mata pelajaran bahasa Melayu sangat penting bagi membolehkan PdPc berasaskan KBAT dapat dijalankan dengan lancar dan berkesan. Tidak dinafikan juga, ketidaksediaan guru bahasa Melayu dalam mengaplikasikan KBAT menyebabkan pengajaran berasaskan KBAT tidak dapat dilaksanakan dengan baik dan penerapan KBAT dalam pembelajaran murid juga turut terganggu. Oleh itu, kertas kerja ini akan merungkai kesediaan dan ketidaksediaan guru bahasa Melayu ataupun guru subjek lain dalam melaksanakan pengajaran berasaskan KBAT sama ada di peringkat pendidikan rendah mahupun di peringkat pendidikan menengah. Kesediaan guru dalam melaksanakan KBAT dalam PdPc bahasa Melayu merupakan aspek penting dalam menjayakan pelaksanaan dan penguasaan KBAT dalam kalangan guru mahupun pelajar.

Jadual 3 menjelaskan tentang tahap kesediaan guru dalam mengaplikasikan KBAT dalam pengajaran. Guru Bahasa Melayu didapati masih belum bersedia sepenuhnya dalam menerapkan KBAT kerana mereka kurang mendapat pendedahan tentang cara pengajaran yang betul berasaskan KBAT. Hal ini disokong oleh Wan Nor Shairah Sharuji dan Norazah Mohd Nordin (2017), menjelaskan bahawa guru kurang bersedia menerapkan KBAT dalam pengajarannya disebabkan oleh kekurangan pendedahan tentang kaedah pengajaran dan pedagogi KBAT. Justeru, pendedahan tentang kaedah pengajaran berasaskan KBAT sangat penting terhadap guru bahasa Melayu agar mereka dapat menjalankan PdPc dengan berkesan dan mudah difahami oleh murid.

Ketidaksediaan guru juga bergantung kepada kemampuan guru bahasa Melayu membina soalan aras tinggi dan tahap penerimaan murid itu sendiri terhadap pembelajaran berasaskan KBAT, misalnya tahap pengetahuan murid dan kebolehan murid menjawab soalan KBAT. Hal ini dikukuhkan dengan dapatan kajian oleh Nooriza Kassim dan Effandi Zakaria (2015), guru sebenarnya dibelenggu oleh beberapa masalah dalam mengaplikasikan KBAT dalam PdPc, iaitu berkaitan dengan tahap pengetahuan asas murid, murid menghadapi kesukaran dalam memenuhi soalan aras tinggi dan kesukaran bagi guru itu sendiri untuk membina soalan beraras tinggi. Walau bagaimanapun, peranan guru sangat diperlukan dalam menjayakan pelaksanaan KBAT di sekolah memandangkan guru merupakan tunjang kecemerlangan pencapaian pelajar dalam memberi tunjuk ajar dan bimbingan kepada pelajar.

Selain itu, guru bahasa Melayu juga dikatakan kurang bersedia dalam menerapkan KBAT kerana tugas mereka bukan hanya tertumpu kepada mengajar malah dibebani oleh tugas-tugas lain yang 
menyebabkan fokus terhadap penerapan KBAT tidak dapat dilaksanakan sepenuhnya. Kajian Rohaida Mazlan dan Zamri Mahamod (2016), mendapati beban tugas guru dalam akademik, hal ehwal pelajar dan kurikulum menjadi salah satu sebab kesediaan guru dalam melaksanakan pengajaran berasaskan KBAT di sekolah kurang memberangsangkan. Walau bagaimanapun, dapatan kajian ini menunjukkan bahawa bukan hanya disebabkan oleh beban tugas guru yang semakin meningkat menyebabkan guru tidak bersedia dalam mengaplikasikan KBAT malah faktor kekurangan strategi juga mendorong ketidaksediaan guru.

Guru Bahasa Melayu juga didapati sangat selesa mengamalkan pengajaran berpusatkan guru yang sememangnya menjadi amalan para guru sejak dahulu lagi merupakan antara sebab mereka tidak bersedia untuk mengaplikasikan KBAT dalam PdPc yang lebih menjurus kepada pengajaran berpusatkan murid. Hal ini sejajar dengan dapatan kajian Nor Hasmaliza Hasan dan Zamri Mahamod (2016), mendapati guru tidak tahu dan tidak jelas tentang cara menerapkan KBAT dalam PdPc dan oleh sebab hal demikian, mereka masih mengamalkan pengajaran secara tradisional, iaitu berpusatkan guru bagi menghabiskan sukatan pelajaran. Sedangkan, pengajaran berpusatkan guru ini akan menyebabkan pelajar menjadi pasif dan membantutkan proses kemahiran berfikir pelajar kerana pelajar hanya mendengar dan menerima maklumat daripada guru sahaja tanpa memberi peluang kepada murid untuk melontarkan pendapat dan pandangannya sendiri tentang apa yang dipelajari ataupun dari aspek yang lain.

Kesediaan guru bahasa Melayu mengaplikasikan pelbagai strategi bagi menerapkan KBAT dalam PdPc sedikit sebanyak membantu para guru untuk lebih bersedia menerapkan KBAT dalam pembelajaran murid. Menurut Avargil, Herscovitz, dan Dori (2012), guru kurang bersedia dalam mengaplikasikan pendekatan dan kaedah pengajaran baru bagi meningkatkan pencapaian murid. Realitinya, guru dapat mengaplikasikan pelbagai strategi bagi memperhebatkan KBAT di dalam bilik darjah sekiranya mereka mendapat sokongan daripada Kementerian Pendidikan Malaysia, menjalinkan hubungan rapat dengan pelajar dan ibu bapa serta didedahkan dengan pelbagai kemudahan belajar.

Penerapan KBAT dalam PdPc bahasa Melayu dapat dijalankan dengan efektif sekiranya guru mempunyai pengetahuan dan kemahiran yang mantap tentang pelaksanaan KBAT. Hal ini disokong oleh Wan Ismail, Muhammad Hamzah, dan M.A Lubis (2016) menegaskan kesediaan guru dalam menerapkan KBAT dilihat dari aspek pengetahuan dan kemahiran guru. Berdasarkan dapatan kajiannya mendapati tahap kesediaan pengetahuan dan kemahiran guru terhadap penerapan KBAT berada pada tahap tinggi, iaitu guru mengetahui konsep, istilah dan makna KBAT serta mempunyai pandangan yang positif ke arah pelaksanaan KBAT. Walau bagaimanapun, kemahiran guru dalam mengaplikasikan KBAT boleh terganggu sekiranya mengalami kekangan masa, kesibukan dengan pelbagai tugasan luar dan fokus untuk menghabiskan sukatan pelajaran. Oleh itu, kesediaan guru bukan sahaja diukur menerusi pengetahuan dan kemahiran guru Bahasa Melayu dalam menerapkan KBAT malah diukur berdasarkan kemampuan guru menyelesaikan sebarang masalah yang menjadi halangan dalam menerapkan KBAT.

Selain daripada kesediaan guru Bahasa Melayu diukur berdasarkan mempunyai pengetahuan dan kemahiran dalam menerapkan KBAT, kesediaan guru turut diukur berdasarkan sikap guru itu sendiri terhadap penerapan KBAT dalam PdPc. Kajian Mohamad Nurul Azmi \& Nurzatulshima Kamarudin (2017), melihat kesediaan guru dalam menerapkan KBAT dari aspek pengetahuan dan sikap guru terhadap pelaksanaan KBAT. Misalnya, guru didapati kurang pengetahuan tentang KBAT, kurang kemahiran terhadap penerapan KBAT dan sikap guru yang tidak menonjolkan komitmen yang tinggi dalam menerapkan KBAT dalam PdPc. Hakikatnya, kesediaan guru dalam mengaplikasikan KBAT bertitik tolak daripada guru mempunyai pengetahuan luas tentang cara pelaksanaan KBAT, mahir dalam menjalankan PdPc berasaskan KBAT dan menunjukkan sikap yang positif dalam pelaksanaan KBAT.

Berikutan penjelasan oleh beberapa orang tokoh berkaitan dengan kesediaan guru dalam melaksanakan KBAT, dapatlah disimpulkan bahawa kesediaan guru dalam melaksanakan PdPc berasaskan KBAT bergantung pada kebolehan guru dalam membina soalan aras tinggi, menyeimbangkan tugas utama guru dengan tugas sampingan, kejelasan para guru tentang bagaimana cara menerapkan KBAT, sokongan orang sekeliling, pemahaman terhadap konsep, istilah dan makna KBAT, tahap pengetahuan terhadap KBAT, kemahiran melaksanakan PdPc KBAT dan sikap terhadap penerapan KBAT dalam pengajaran. Kesediaan guru dalam menjalankan PdPc KBAT merupakan aspek utama bagi menjayakan pelaksanaan KBAT dalam sistem pendidikan negara Malaysia. 
JADUAL 3 Kesediaan Guru dalam Kemahiran Berfikir Aras Tinggi (KBAT)

\begin{tabular}{|c|c|c|c|}
\hline Bil. & Nama Penulis & Tajuk Kajian dan Tahun & Kesediaan Guru \\
\hline 1 & $\begin{array}{l}\text { Wan Nor Shairah } \\
\text { Sharuji dan } \\
\text { Norazah Mohd } \\
\text { Nordin }\end{array}$ & $\begin{array}{l}\text { Kesediaan Guru dalam Melaksanakan } \\
\text { Kemahiran Berfikir Aras Tinggi (2017) }\end{array}$ & $\begin{array}{l}\text { "guru kurang bersedia dalam menerapkan } \\
\text { KBAT disebabkan oleh kurangnya } \\
\text { pendedahan tentang kaedah pengajaran } \\
\text { dan pedagogi KBAT...". }\end{array}$ \\
\hline 2 & $\begin{array}{l}\text { Nooriza Kassim } \\
\text { dan Effandi } \\
\text { Zakaria }\end{array}$ & $\begin{array}{l}\text { Integrasi Kemahiran Berfikir Aras Tinggi } \\
\text { dalam Pengajaran dan Pembelajaran } \\
\text { Matematik: Analisis Keperluan Guru } \\
\text { (2015) }\end{array}$ & $\begin{array}{l}\text { “... guru dibelenggu dengan masalah } \\
\text { dalam mengaplikasikan } \quad \text { KBAT, } \\
\text { antaranya menghadapi kesukaran dalam } \\
\text { membina soalan aras tinggi”. }\end{array}$ \\
\hline 3 & $\begin{array}{l}\text { Rohaida Mazlan } \\
\text { dan Zamri } \\
\text { Mahamod }\end{array}$ & $\begin{array}{l}\text { Faktor-Faktor yang Mempengaruhi } \\
\text { Kesediaan Guru Bahasa Melayu } \\
\text { Melaksanakan Kajian Pengajaran (2016) }\end{array}$ & $\begin{array}{l}\text { “...beban tugas guru dalam akademik, hal } \\
\text { ehwal pelajar dan kurikulum merupakan } \\
\text { penyebab kesediaan guru kurang } \\
\text { memberangsangkan". }\end{array}$ \\
\hline 4 & $\begin{array}{l}\text { Nor Hasmaliza } \\
\text { Hasan dan Zamri } \\
\text { Mahamod }\end{array}$ & $\begin{array}{l}\text { Persepsi Guru Bahasa Melayu Sekolah } \\
\text { Menengah Terhadap Kemahiran Berfikir } \\
\text { Aras Tinggi (2016) }\end{array}$ & $\begin{array}{l}\text { “... guru tidak tahu dan tidak jelas tentang } \\
\text { bagaimana untuk menerapkan } \\
\text { dalam PdPA oleh kerana } \\
\text { mengamalkan pengajaran } \\
\text { tradisional dan berpusatkan guru bagi } \\
\text { menghabiskan sukatan pelajaran". }\end{array}$ \\
\hline 5 & $\begin{array}{l}\text { Avargil, Herscovitz } \\
\text { dan Dori }\end{array}$ & $\begin{array}{l}\text { Teaching Thinking Skills in Context-Based } \\
\text { Learning: Teacher's Challenges and } \\
\text { Assessment Knowledge (2012) }\end{array}$ & $\begin{array}{l}\text { “... guru dapat mengaplikasikan dan } \\
\text { memperhebatkan KBAT dalam bilik } \\
\text { darjah sekiranya mendapat sokongan } \\
\text { daripada Kementerian Pendidikan, } \\
\text { hubungan rapat dengan pelajar, dan ibu } \\
\text { bapa pelajar dan dengan pendedahan } \\
\text { kemudahan belajar". }\end{array}$ \\
\hline 6 & $\begin{array}{l}\text { Wan Ismail, } \\
\text { Muhammad } \\
\text { Hamzah dan M.A } \\
\text { Lubis }\end{array}$ & $\begin{array}{l}\text { Kesediaan Guru Pendidikan Islam Sekolah } \\
\text { Rendah Terhadap Penerapan KBAT dalam } \\
\text { Pengajaran dan Pembelajaran (2016) }\end{array}$ & $\begin{array}{l}\text { “... kesediaan guru tinggi kerana guru } \\
\text { mengetahui konsep, istilah dan makna } \\
\text { KBAT serta mempunyai pandangan yang } \\
\text { positif ke arah pelaksanaan KBAT”. }\end{array}$ \\
\hline 7 & $\begin{array}{l}\text { Mohamad Nurul } \\
\text { Azmi dan } \\
\text { Nurzatulshima } \\
\text { Kamaruddin }\end{array}$ & $\begin{array}{l}\text { Penerapan Kemahiran Berfikir Aras } \\
\text { Tinggi (KBAT): Kesediaan Guru dalam } \\
\text { Pengajaran dan Pembelajaran Reka } \\
\text { Bentuk dan Teknologi (RBT) di Sekolah } \\
\text { Rendah (2017) }\end{array}$ & $\begin{array}{llr}\text { “... guru kurang pengetahuan tentang } \\
\text { KBAT, kurang kemahiran terhadap } \\
\text { penerapan KBAT dan sikap guru tidak } \\
\text { menonjolkan komitmen r dalam } \\
\text { menerapkan KBAT”. }\end{array}$ \\
\hline
\end{tabular}




\section{KEPERLUAN GURU DALAM MELAKSANAKAN KEMAHIRAN BERFIKIR ARAS TINGGI (KBAT)}

Dalam menjayakan pelaksanaan KBAT dalam kalangan guru Bahasa Melayu, guru sudah semestinya mempunyai pemahaman KBAT yang mencukupi, pengetahuan KBAT yang mencukupi, kemahiran dalam mengajar KBAT dan sikap yang positif terhadap penerapan KBAT dalam PdPc. Justeru, keperluan guru terhadap penerapan KBAT dalam PdPc mestilah diberi perhatian agar para guru dapat melaksanakan KBAT secara berkesan dan menepati kehendak Kementerian Pendidikan supaya murid dan guru dapat menguasai KBAT.

Jadual 4 menunjukkan antara keperluan guru yang dinyatakan oleh beberapa orang tokoh. Salah satu daripada keperluan guru Bahasa Melayu dalam menjayakan pelaksanaan PdPc berasaskan KBAT, mereka memerlukan pendedahan kursus secara berterusan dan lebih berfokus terhadap sesuatu subjek yang diajar. Walau bagaimanapun, tidak dinafikan bahawa telah banyak kursus-kursus berkaitan KBAT telah dilaksanakan tetapi kebanyakannya kursus yang bersifat general seperti memberi penekanan terhadap peta-peta pemikiran dan kaedah penyoalan sahaja (Nooriza Kassim \& Effandi Zakaria, 2015; Wan Nor Shairah Sharuji \& Norazah Mohd Nordin, 2017). Realitinya, guru-guru memerlukan kursus yang lebih khusus yang berfokuskan kepada cara pelaksanaan KBAT berdasarkan satu-satu subjek pelajaran agar mereka dapat mengaplikasikannya dengan lebih berkesan bukan sekadar mengetahui secara teori sahaja, malah dapat melaksanakannya secara praktikal sebagaimana sepatutnya semua guru dapat laksanakan PdPc berasaskan KBAT dengan jayanya.

Selain itu, guru bahasa Melayu juga memerlukan modul sebagai penekanan untuk melaksanakan pengajaran berasaskan KBAT. Penyediaan modul dalam melaksanakan KBAT ini bukan sahaja menjadi garis panduan dan bimbingan kepada guru tentang cara untuk melaksanakan KBAT dalam pengajaran. Guru-guru akan lebih bersedia dan berkeyakinan dengan penyediaan modul bagi menerapkan KBAT dalam PdPc dan juga dapat mengubah cara pengajaran guru daripada bersifat tradisional kepada pengajaran berasaskan KBAT. Selain kursus dan juga modul, guru-guru juga memerlukan bahan sumber dalam menerapkan KBAT dalam PdPc. Bahan sumber sebenarnya memainkan peranan penting sebagai panduan kepada aktiviti soal jawab antara murid dengan guru dan juga berperanan menyediakan cadangan bagi aktiviti berbentuk hand-on.

Guru Bahasa Melayu juga memerlukan pendedahan tentang konsep KBAT dan cara pengaplikasian KBAT dalam PdPc yang sebetulnya sebagaimana yang dikehendaki oleh Kementerian Pendidikan Malaysia. Hal ini disokong oleh kajian Nor Hasmaliza Hasan \& Zamri Mahamod (2016), guru-guru perlu didedahkan secara menyeluruh tentang konsep KBAT dan cara pelaksanaan KBAT dilakukan di sekolah serta penambahbaikan kandungan kursus Bahasa Melayu tentang KBAT agar memberi kefahaman dengan jelas kepada guru dalam pelbagai aspek bagi menentukan penerapan KBAT dalam pengajaran dijalankan dengan teratur dan konsisten.

Manakala Hasnah Isnon dan Jamaludin Badusah (2017), juga telah menyenaraikan beberapa keperluan guru dalam melaksanakan KBAT, iaitu guru-guru memerlukan penyediaan kemudahan di sekolah yang mencukupi seperti kemudahan ICT dan buku panduan bagi melaksanakan pengajaran berasaskan KBAT. Hal ini demikian kerana, dengan penyediaan kemudahan pengajaran KBAT, guru bahasa Melayu dapat menjalankan PdPc dengan lancar di samping dapat meningkatkan keberkesanan penerapan KBAT dalam kalangan murid mahupun guru itu sendiri dalam menguasai KBAT.

Menurut Norakma, Abdul Razak, dan Noria Munirah (2015) dan Nur Athirah \& Faridah (2017), keperluan guru dari segi pendedahan tentang konsep, pendekatan dan strategi pelaksanaan KBAT secara mendalam sering kali menjadi isu terhadap ketidaksediaan guru dalam melaksanakan PdPc berasaskan KBAT dan juga faktor kepada guru masih mengamalkan pengajaran secara tradisional. Tambahan pula, guru-guru juga memerlukan kursus secara berterusan dan konsisten bagi membolehkan guru betul-betul memahami dan menguasai KBAT secara keseluruhannya.

Menurut Mohamad Nurul Azmi dan Nurzatulshima Kamarudin (2017), guru-guru hanya didedahkan dengan kursus tentang KBAT semata-mata dan kurang didedahkan secara khusus tentang kursus KBAT yang menjurus kepada sesuatu subjek. Oleh hal yang demikian, guru-guru menghadapi kesukaran dalam melaksanakan KBAT dalam pengajaran mereka walaupun mempunyai pengetahuan tentang KBAT. Berdasarkan dapatan kajian ini, guru-guru RBT mengalami masalah dalam menerapkan KBAT bagi subjek tersebut memandangkan subjek tersebut baharu diperkenalkan. Justeru, pendedahan 
secara khusus tentang pelaksanaan KBAT dalam subjek RBT sangat diperlukan oleh para guru bagi meningkatkan pengetahuan dan juga pemahaman mereka di samping dapat menjalankan PdPc secara berkesan. Tambahan pula, selain daripada pendedahan kursus KBAT dalam subjek RBT sudah semestinya para guru juga memerlukan modul dan juga bahan bantu sebagai garis panduan dalam menjayakan lagi pelaksanaan KBAT dalam PdPc RBT dan begitu juga bagi semua subjek.

Berdasarkan beberapa penjelasan tokoh berkaitan dengan keperluan guru dalam melaksanakan KBAT dapatlah disimpulkan bahawa para guru memerlukan pendedahan kursus KBAT yang berfokuskan sesuatu subjek, memerlukan modul pengajaran KBAT, bahan sumber yang membantu PdPc KBAT, pendedahan tentang konsep KBAT berserta dengan cara bagaimana KBAT diterapkan dan pemurnian terhadap kandungan kursus bersesuaian dengan KBAT. Sekiranya semua keperluan guru-guru dalam melaksanakan KBAT dapat disediakan dan dimurnikan nescaya guru Bahasa Melayu mahupun guru yang mengajar subjek lain dapat menjalankan PdPc berasaskan KBAT dengan jayanya dan dapat melahirkan murid yang menguasai KBAT dengan mudah.

JADUAL 4 Keperluan Guru dalam Melaksanakan Kemahiran Berfikir Aras Tinggi (KBAT)

\begin{tabular}{|c|c|c|c|}
\hline Bil. & Nama Penulis & Tajuk Kajian dan Tahun & Keperluan Guru \\
\hline \multirow[t]{2}{*}{1} & $\begin{array}{l}\text { Nooriza Kassim dan } \\
\text { Effandi Zakaria }\end{array}$ & $\begin{array}{l}\text { Integrasi Kemahiran Berfikir } \\
\text { Aras Tinggi dalam } \\
\text { Pengajaran dan Pembelajaran } \\
\text { Matematik: Analisis } \\
\text { Keperluan Guru (2015) }\end{array}$ & \multirow{2}{*}{$\begin{array}{l}\text { "Guru-guru memerlukan pendedahan } \\
\text { kursus secara berterusan dan lebih } \\
\text { berfokus kepada sesuatu subjek.” } \\
\text { “...guru-guru juga memerlukan modul } \\
\text { sebagai penekanan untuk melaksanakan } \\
\text { pengajaran berasaskan KBAT.” } \\
\text { “...guru-guru juga memerlukan bahan } \\
\text { sumber dalam menerapkan KBAT } \\
\text { dalam PdPc.” }\end{array}$} \\
\hline & $\begin{array}{l}\text { Wan Nor Shairah Sharuji } \\
\text { dan Norazah Mohd Nordin }\end{array}$ & $\begin{array}{l}\text { Kesediaan Guru dalam } \\
\text { Melaksanakan Kemahiran } \\
\text { Berfikir Aras Tinggi (2017) }\end{array}$ & \\
\hline 2 & $\begin{array}{l}\text { Nor Hasmaliza Hasan dan } \\
\text { Zamri Mahamod }\end{array}$ & $\begin{array}{l}\text { Persepsi Guru Bahasa Melayu } \\
\text { Sekolah Menengah Terhadap } \\
\text { Kemahiran Berfikir Aras } \\
\text { Tinggi (2016) }\end{array}$ & $\begin{array}{l}\text { "....guru-guru perlu didedahkan secara } \\
\text { menyeluruh tentang konsep KBAT dan } \\
\text { bagaimana pelaksanaan KBAT } \\
\text { dilalukan di sekolah." }\end{array}$ \\
\hline & & & $\begin{array}{l}\text { "Kandungan kursus tentang KBAT juga } \\
\text { perlu dibuat penambahbaikan supaya } \\
\text { dapat memberi kefahaman dengan jelas } \\
\text { kepada guru..." }\end{array}$ \\
\hline 3 & $\begin{array}{l}\text { Hasnah Isnon dan } \\
\text { Jamaludin Badusah }\end{array}$ & $\begin{array}{l}\text { Kompetensi Guru Bahasa } \\
\text { Melayu dalam Menerapkan } \\
\text { Kemahiran Berfikir Aras } \\
\text { Tinggi dalam Pengajaran dan } \\
\text { Pembelajaran (2017) }\end{array}$ & $\begin{array}{l}\text { "...guru-guru memerlukan penyediaan } \\
\text { kemudahan di sekolah yang mencukupi } \\
\text { seperti kemudahan ICT dan buku } \\
\text { panduan bagi melaksanakan pengajaran } \\
\text { berasaskan KBAT.” }\end{array}$ \\
\hline
\end{tabular}




\begin{tabular}{|c|c|c|c|}
\hline 4 & $\begin{array}{l}\text { Norakma, Abdul Razak, } \\
\text { dan Noria Munirah }\end{array}$ & $\begin{array}{l}\text { Pembelajaran Berteraskan } \\
\text { Kemahiran Berfikir Aras } \\
\text { Tinggi (KBAT) di dalam } \\
\text { Pengajaran dan Pembelajaran } \\
\text { Mata Pelajaran Sejarah } \\
\text { (2015) }\end{array}$ & $\begin{array}{l}\text { "...keperluan guru dari segi pendedahan } \\
\text { tentang konsep, pendekatan dan strategi } \\
\text { pelaksanaan KBAT secara } \\
\text { mendalam..." }\end{array}$ \\
\hline & Nur Athirah dn Faridah & $\begin{array}{l}\text { Kesediaan Guru Prasekolah } \\
\text { dalam Melaksanakan KBAT } \\
\text { dalam Pengajaran dan } \\
\text { Pembelajaran (2017) }\end{array}$ & $\begin{array}{l}\text { "...guru-guru juga memerlukan kursus } \\
\text { secara berterusan dan konsisten bagi } \\
\text { membolehkan guru betul-betul } \\
\text { memahami dan menguasai KBAT secara } \\
\text { keseluruhannya." }\end{array}$ \\
\hline 5 & $\begin{array}{l}\text { Mohamad Nurul Azmi dan } \\
\text { Nurzatulshima } \\
\text { Kamaruddin }\end{array}$ & $\begin{array}{l}\text { Penerapan Kemahiran } \\
\text { Berfikir Aras Tinggi (KBAT): } \\
\text { Kesediaan Guru dalam } \\
\text { Pengajaran dan Pembelajaran } \\
\text { Reka Bentuk dan Teknologi } \\
(\text { RBT) di Sekolah Rendah } \\
(2017)\end{array}$ & $\begin{array}{l}\text { “...kurang didedahkan secara khusus } \\
\text { tentang kursus KBAT yang menjurus } \\
\text { kepada sesuatu subjek...” } \\
\text { "... memerlukan modul dan juga bahan } \\
\text { bantu sebagai garis panduan dalam } \\
\text { menjayakan lagi pelaksanaan KBAT.” }\end{array}$ \\
\hline
\end{tabular}

\section{KESIMPULAN}

Peranan guru dalam menjayakan pelaksanaan Kemahiran Berfikir Aras Tinggi (KBAT) di sekolah dalam semua subjek sangat penting bagi melahirkan generasi sebagaimana yang diperlukan pada abad ke-21, iaitu generasi yang menguasai KBAT supaya dapat bersaing di peringkat global serta dapat meningkatkan kedudukan sistem pendidikan Malaysia di persada antarabangsa. Seperti yang sedia maklum, guru merupakan tunjang dalam mendidik murid agar memperoleh prestasi cemerlang dalam semua subjek. Oleh hal yang demikian, dalam menerapkan KBAT dalam semua mata pelajaran, guru terlebih dahulu perlu memahami dan menguasai KBAT agar proses pengajaran KBAT dapat dijalankan dengan lancar dan berkesan. Walau bagaimanapun, berdasarkan beberapa kajian terdahulu mendapati masih terdapat guru-guru yang belum bersedia dalam menerapkan KBAT dalam pengajaran mereka dan oleh hal sedemikian sedikit sebanyak menjejaskan pelaksanaan KBAT secara berkesan terhadap pelajar.

Berdasarkan penelitian terhadap kajian-kajian terdahulu, kebanyakan guru masih belum bersedia melaksanakan KBAT dalam pengajarannya disebabkan oleh kurang pendedahan tentang cara pelaksanaan KBAT dalam PdPc, tidak tahu bagaimana untuk menerapkan KBAT dalam PdPc dan juga dibebani dengan pelbagai tugas lain yang menghalang untuk melaksanakan PdPc berasaskan KBAT dilaksanakan dengan baik. Dapatan kajian ini juga turut memperincikan beberapa keperluan yang diperlukan oleh guru dalam melaksanakan pengajaran berasaskan KBAT. Namun, selain daripada mengetahui tahap kesediaan dan keperluan guru dalam melaksanakan pengajaran berasaskan KBAT khususnya bagi guru Bahasa Melayu, perincian tentang strategi pengajaran KBAT dalam pengajaran guru Bahasa Melayu juga perlu dititikberatkan agar PdPc KBAT dapat dilaksanakan dengan lebih berkesan dan bermakna. Antara aspek kajian berkaitan KBAT yang dikenal pasti belum diteliti dengan lebih mendalam ialah strategi penerapan KBAT dalam pengajaran guru Bahasa Melayu secara umum ataupun khusus di peringkat sekolah rendah. Penelitian terhadap strategi penerapan KBAT oleh guru Bahasa Melayu merupakan salah satu aspek utama yang perlu diberi perhatian kerana keberkesanan strategi penerapan KBAT merupakan tunjang kepada penguasaan KBAT dalam pembelajaran bahasa 
Melayu murid. Oleh itu, diharapkan agar ada pengkaji-pengkaji lain yang akan meneroka tentang strategi penerapan KBAT dalam pengajaran guru tidak kira dalam apa-apa subjek sekalipun.

\section{RUJUKAN}

Abdul Halim Abdullah, Johari Surif, Norhasniza Ibrahim. (2014). PISA 2012: Di mana kedudukan Malaysia untuk subjek Matematik? Prosiding Seminar Antarabangsa Kelestarian Insan, (April).

Abdul Rasid Jamiam, Shamsudin Othman, Azhar Mohd Sabil, dan Juanes Masamin. (2016). Kesediaan guru dalam pelaksanaan kemahiran berfikir terhadap pengajaran penulisan karangan murid bukan Melayu. PENDETA Journal of Malay Language, Education and Literature, 7(1), 1-8.

Anderson, L.W., dan Krathwohl, D.R. (2001). A taxonomy for learning, teaching, and assessing: A Revision of Bloom's Taxonomy of Education Objectives. Theory Into Practice (Vol. Compete e,p. xxix, 352p.) doi:10.1207/s15430421tip4104_2. Diakses pada 12 Mac 2018.

Afinde Othman. (2016). Pengetahuan, Kemahiran dan Amalan Guru Membina Item KBAT dalam Instrumen Pentaksiran Pembelajaran. Universiti Tun Hussein Onn Malaysia, Batu Pahat: Tesis Sarjana.

Avargil, S., Herscovitz, O., dan Dori, Y. J. (2012). Teaching thinking skills in context-based learning: teachers' challenges and assessment knowledge. Journal of Science Education and Technology, 21(2), 207-225. https://doi.org/10.1007/s10956-011-9302-7. Diakses pada 5 Julai 2018.

Bahagian Pembangunan Kurikulum. (2014). Kemahiran berfikir aras tinggi: Aplikasi di sekolah. Kementerian Pendidikan Malaysia. https://doi.org/10.1017/CBO9781107415324.004. Diakses pada 6 Mac 2018.

Bakry, Md. Nor Bakar, \& Firdaus. (2013). Kemahiran berfikir aras tinggi di kalangan guru Matematik sekolah menengah pertama di Kota Makassar. 2nd International Seminar on Quality and Affordable Education (ISQAE) 2013, (Isqae), 172-175.

Halimah Md Shariff. (2009). Peranan Minda dalam Kemahiran Berfikir. (Tajularipin Sulaiman \& Aminuddin Hassan, Eds.). Serdang: Penerbit Universiti Putra Malaysia.

Hasnah Isnon dan Jamaludin Badusah. (2017). Kompetensi guru Bahasa Melayu dalam menerapkan kemahiran berfikir aras tinggi dalam pengajaran dan pembelajaran (Malay language teacher competency to implementation higher order thinking skill in teaching and learning). Malay Language Education Journal MyLEJ, 7(1), 2180-4842. Retrieved from http://journalarticle.ukm.my/10413/1/133-256-1-SM.pdf. Diakses pada 16 Mac 2018.

Kementerian Pendidikan Malaysia. (2014). Elemen KBAT dalam Pedagogi. Bahagian Pembangunan Kurikulum. https://doi.org/10.1007/s13398-014-0173-7.2. Diakses pada 4 April 2018.

Logeswar Arumugam, Ainun Omar, Raja Nor Safinas Raja Harun, dan Nurfilzah Zainal. (2016). Issues related to the teaching and learning of higher order thinking skills among TESL student teachers. Proceedings of the 1st English Education International Conference (EEIC), 451-456.

Mohamad Nurul Azmi dan Nurzatulshima Kamarudin. (2017). Penerapan kemahiran berfikir aras tinggi (KBAT): Kesediaan guru dalam pengajaran dan pembelajaran reka bentuk dan teknologi (RBT) di sekolah rendah. International Research Journal of Education and Sciences (IRJES), 1(1), 1-5.

Nooriza Kassim, Effandi Zakaria. (2015). Integrasi kemahiran berfikir aras tinggi dalam pengajaran dan pembelajaran matematik: Analisis keperluan guru (Integration of higher order thinking skills in the teaching and learning of mathematics: Teachers' needs analysis). Jurnal Pendidikan Matematik, 3(1), 1-12. Retrieved from http://www.jupema.org/index.php/jpm/article/view/001312015\%5Cnhttp:// www.jupema.org/index.php/jpm/article/download/001312015/17. Diakses pada 2 Mac 2018.

Nor Hasmaliza Hasan, Zamri Mahamod. (2016). Persepsi guru bahasa Melayu sekolah menengah terhadap kemahiran berfikir aras tinggi (The perception of Malay language teachers at secondary school towards higher order thinking skills). Malay Language Education Journal - MyLEJ, 6(2), 2180-4842.

Norakma Mohd Daud, Abdul Razak Ahmad, Noria Munirah Yakub. (2015). Pembelajaran berteraskan kemahiran berfikir aras tinggi (KBAT) di dalam pengajaran dan pembelajaran mata pelajaran Sejarah. 7th International Seminar on Regional Education, 1, 352-360.

Nur Athirah Ariffin dan Faridah Yunus. (2017). Kesediaan guru prasekolah melaksanakan KBAT dalam pengajaran dan pembelajaran. Simposium Pendidikan di Peribadikan: Perspektif Risalah An-Nur (SPRiN2017), 147-152. Retrieved from http://conference.ukm.my/sprin/index.php/sprin/sprin/paper/viewFile/56/21. Diakses pada 9 Mei 2018.

Raja Noraina Raja Rahim. (2018). KBAT di Landasan Tepat. https://www.bharian.com.my/berita/pendidikan/2018/03/400667/kbat-di-landasan-tepat. Diakses pada Mei 2018. 
Rajendran Nagappan. (2002). Bahasa Melayu: Penyumbang ke arah penguasaan kemahiran berfikir aras tinggi. Persidangan Antarabangsa Pengajian Melayu Kedua, 1-13.

Rohaida Mazlan dan Zamri Mahamod. (2016). Faktor-faktor yang mempengaruhi kesediaan guru Bahasa Melayu melaksanakan kajian pengajaran. Jurnal Pendidikan Malaysia, 41(2), 173-182.

Suzana Abd Mutalib, dan Mohammad Zeeree Kanreng. (2017). Pelaksanaan KBAT dalam pentaksiran formatif bagi slot tunjang komunikasi Bahasa Melayu: Kajian kes. Jurnal Pendidikan Awal Kanak-Kanak, 6. Retrieved from http://ejournal.upsi.edu.my/journal/JPAK. Diakses pada 18 Mei 2018.

W.A Wan Ismail, Muhammad Hamzah, dan M.A Lubis. (2016). Kesediaan guru pendidikan Islam sekolah rendah di Selangor terhadap penerapan KBAT dalam pengajaran dan pembelajaran (Readiness of Islamic education teacher in Selangor's primary school in the implementation of KBAT in teaching and learning). Akademia. Journal of Advanced Research in Applied Sciences and Engineering Technology, 3(1), 79-92.

Wan Nor Shairah Sharuji dan Norazah Mohd Nordin. (2017). Kesediaan guru dalam pelaksanaan Kemahiran Berfikir Aras Tinggi (KBAT). Simposium Pendidikan, 1(2017), 140-146. 